\title{
High Intensity Ultrasound-Induced Crystallization of Mango Kernel Fat
}

\author{
Sopark Sonwai ${ }^{1}$, Pimwalan Ornla-ied ${ }^{1}$, Silvana Martini ${ }^{2}$, Hironori Hondoh ${ }^{3}$, and S. Ueno ${ }^{4}$ \\ ${ }^{1}$ Silpakorn University \\ ${ }^{2}$ Utah State University \\ ${ }^{3}$ University of Shizuoka \\ ${ }^{4}$ Hiroshima University
}

April 28, 2020

\begin{abstract}
The crystallization behavior of mango kernel fat (MKF) at $25{ }^{\circ} \mathrm{C}$ with and without the application of high-intensity ultrasound (HIU) $(20 \mathrm{kHz}, 125 \mathrm{~W})$ was studied as a function of ultrasound amplitude level $(30 \%, 50 \%$ and $70 \%$ of the maximum amplitude of $180 \mu \mathrm{m})$. The irradiation time was fixed at $5 \mathrm{~s}$. It was found that HIU induced MKF crystallization. The crystallization induction time decreased with a decrease in crystal size and an increase in the number of crystals as the HIU amplitude increased. The $\beta$ '-b transformation was also accelerated with HIU application. This work has shown that there is a great potential for the use of HIU in the food industry to achieve a shorter and more controllable crystallization process. In particular, HIU could be used as an efficient tool for controlling the polymorphic transition of fats.
\end{abstract}

\section{Introduction}

Crystallization is a process used in many industrial domains including food, chemical, pharmaceutical and petrochemical industries (Mulin, 2001). Recently, there has been increasing interest in the application of ultrasonic waves to crystallization (called sonocrystallization). High-intensity ultrasound (HIU) is an invasive technique that uses acoustic waves operating at low frequency $(20-100 \mathrm{kHz})$ and high power (10$10,000 \mathrm{~W} / \mathrm{cm}^{2}$ ) (Ye and Martini, 2015). In general, HIU can assist various processes in food technology involving crystallization (Mason et al., 1996). In particular, the application of HIU to the nucleation and crystallization of fats has been a great deal of interest because of its ability to change their functional properties controllably (Ueno et al., 2003).

HIU causes cavitation, which refers to a series of compressions and rarefactions leading to the formation and implosion of vapor cavities or bubbles (Patist and Bates, 2008). Cavitation is associated with high localized temperatures, high shear forces and high pressures that lead to several physicochemical changes in the material (Soria and Villamiel, 2010). As for the effects on crystallization, HIU influences both nucleation and crystal growth by creating new additional nucleation sites in the crystallization medium (Frydenberg, et al., 2013; Silva et al., 2017). HIU has been reported to (a) induce the nucleation at much lower supersaturation levels, (b) shorten the induction time between the establishment of supersaturation and the onset of nucleation and crystallization, (c) reduce crystal agglomeration, (d) give smaller and more uniform crystal sizes, (e) control the polymorphic crystallization of fats, and (f) increase the hardness as a result of an altered microstructure (Ueno et al., 2003; Luque de Castro and Priego-Capote, 2007; Suzuki et al., 2010; Frydenberg et al., 2013). HIU has also been shown to improve crystalline products and provide a feasible method for industrialized reaction crystallization ( $\mathrm{Li}$ et al., 2006). The degree of supercooling, HIU application settings and a combination of both parameters influence the degree of the HIU effect on the 
crystallization behavior (Martini et al., 2008). Chen et al. (2013) mentioned that the effects of HIU were more significant at higher power level and longer irradiation time. However, the amount of heat generated during long sonication time can offset the effect of HIU. Ye at al. (2011) suggested that the effect of HIU on secondary nucleation, where HIU was applied in the presence of crystals, was more significant than the one observed for primary nucleation. In addition, HIU has been shown to promote the formation of a stable polymorphic structure in lipid systems such as cocoa butter (CB) and tripalmitin (Higaki et al. 2001; Ueno et al., 2003). A previous work by Higaki et al. (2001) on the effect of HIU on the crystallization of confectionery fats has indicated the possibility of HIU-assisted tempering of CB.

Mango is one of the most important fruit crops of Asia. The fat extracted from the mango seeds, called mango kernel fat (MKF), has received attention in recent years due to the resemblance between its melting and crystallization characteristics and those of CB. MKF contains high content of stearic (S) and oleic acids (O) with SOS as its main triacylglycerol (TAG) component (Sonwai et al., 2014) and hence can be used as confectionery fat. According to the EU chocolate directive (2000/36/EC), MKF is one of only six vegetable fats which are allowed to be used for up to $5 \%$ in chocolate (Wilson 1999). Therefore, MKF has a potential to be used as an ingredient for the production of cocoa butter equivalent (CBE). CBEs are vegetable fats that have chemical and physical properties similar to $\mathrm{CB}$ and have been used in chocolate products for many years. It can be added to CB in any proportion without causing significant softening effect, nor altering the melting, rheological and processing characteristics of CB. By adding CBE into chocolate to partially replace $\mathrm{CB}$, both fats will go through tempering process to induce the crystallization of the stable polymorph during chocolate processing.

This paper presents experimental results on the effects of HIU on the crystallization behavior of MKF. The crystallization kinetics, crystal microstructure and polymorphic forms of the fat were studied by controlling the duration of ultrasound application to the liquid fat prior to crystallization. The objective of this study was to gain insight into the possibility of tempering MKF using HIU and to provide a rational way of controlling the polymorphism and nucleation rate by HIU in this industrially relevant system.

\section{Materials and Methods}

\section{Materials}

Mango seeds were obtained from canned fruit factories in Ratchaburi province, Thailand. The seeds were cut open and the seed kernels were removed. The kernels were dried at $65{ }^{\circ} \mathrm{C}$ in a vacuum oven until the moisture content was less than $10 \%$. After that, the dried kernels were finely ground into powder. Then, MKF was extracted from the seed kernels following the method described elsewhere (Sonwai et al., 2014). The fat was kept away from light and air at $4{ }^{\circ} \mathrm{C}$ until further use. The standards for TAG analysis were purchased from Sigma Chemical Co. (St. Louis, MO, USA). Acetone and acetonitrile were of HPLC grade from Burdick and Jackson (Muskegon, MI, USA). All other chemicals were of analytical and HPLC grades.

\section{Sonocrystallization}

HIU-induced crystallization was carried out using an ultrasound generator (model Q125; QSonica, LLC, Newtown, CT., U.S.A.) at $20 \mathrm{kHz}$ and $125 \mathrm{~W}$ and a $1 / 8$ " ultrasound probe (model CL-18). Liquid MKF $(5 \mathrm{~mL})$ was put into a $15 \mathrm{~mL}$ centrifuge tube and placed in a water bath set at $70 \operatorname{deg}$ for $10 \mathrm{~min}$ to completely melt the sample. Then it was poured into a specially designed glass cell (Ueno et al., 2003) jacketed by circulating water and connected to a thermostat. The temperature of the sample inside the glass cell was maintained at $25+-0.5 \mathrm{degC}$ by water circulation. When the sample temperature reached 25 $\operatorname{deg} \mathrm{C}$, the timing was started and HIU was applied for $5 \mathrm{~s}$ and the sample was allowed to crystallize for 60 min. During that period, the crystallization of the sample was followed using different techniques. The HIU amplitude was varied from $30 \%$ to $50 \%$ and $70 \%$ of the maximum value $(180 \mu \mathrm{m})$. During sonication the sample temperature increased to approximately $25.7,29.2$ and $32.8{ }^{\circ} \mathrm{C}$ for the HIU amplitudes of 30,50 and $70 \%$, respectively, before decreasing to $25^{\circ} \mathrm{C}$. 


\section{Transmitted Light Intensity Measurement}

The crystallization induction time and the crystallization behavior of MKF without and with the application of HIU were characterized using a light intensity measurement probe (PASCO airlink) connected with a light sensor. Light intensity is normally regarded as secondary tools to study crystallization, because the data analysis is not straightforward (Tiang and Dealy, 2012). However, it is a simple technique to use and is more useful for probing early kinetics than well-established techniques such as dilatometry, differential scanning calorimetry (DSC), x-ray scattering, optical microscopy and pulsed-nuclear magnetic resonance (Fritsch et al., 2006; Wright et al., 2000). A laser pointer was used as a light source. It was positioned so that the light went through the sample inside the glass cell and was received on the opposite side of the sample by the light detector. Changes in the transmitted light intensity signal during crystallization were monitored by the software SPARKvue (Roseville, CA 95747 USA) that was linked to the light detector. As the sample began to crystallize, less light could go through the sample, resulting in the drop in the transmitted intensity. The recorded light intensity was normalized so that the maximum intensity for each sample was set to be 1 and the minimum intensity was set to be 0 .

\section{Crystal microstructure}

The crystal morphology of MKF crystallized with and without the application of HIU was observed using a polarized light microscope (Olympus BX51, Olympus Corp., Tokyo, Japan), with images captured using a digital video camera (Canon-DS126431, Canon Inc., Japan). After the HIU was applied to the sample for $5 \mathrm{~s}$ at $25{ }^{\circ} \mathrm{C}, 3 \mu \mathrm{L}$ of the sample was placed on a glass slide and covered by a cover slip. The temperature of the glass slide and the cover slip was maintained at $25{ }^{\circ} \mathrm{C}$ by storing them in a temperature-controlled cabinet prior use. The temperature of the sample was set constant at $25^{\circ} \mathrm{C}$ for $60 \mathrm{~min}$ using a temperature controller (computer-controlled hot stage; Linkam LK-600PM, with cooling unit; Linkam L-600A, Linkam Scientific Instruments, Ltd., UK). Crystal image was captured at $1 \mathrm{~min}$ and at every $10 \mathrm{~min}$ of the isothermal time.

\section{Melting characteristic}

The melting thermogram of the sample was determined using the DSC (Model D8000, Perkin-Elmer Co., USA). At $\mathrm{t}=5,15,30,45$ and $60 \mathrm{~min}$ of the crystallization time, $3-5 \mathrm{mg}$ of the sample was withdrawn from the glass cell and placed in an aluminum pan and hermetically sealed. An empty aluminum pan was used as a reference. The sample was heated from $25{ }^{\circ} \mathrm{C}$ to $60{ }^{\circ} \mathrm{C}$ at a rate of $5{ }^{\circ} \mathrm{C} / \mathrm{min}$. The melting profiles were analyzed by the software provided with the DSC (Pyris software, Perkin-Elmer, Shelton, CT, USA).

\section{Polymorphic structure}

The crystal polymorphic form of MKF was determined by a powder x-ray diffractometer (Rigaku RINTTTR, Rigaku Corporation, Tokyo, Japan). The wavelength was $1.54 \AA(\mathrm{CuK} \alpha)$. Scans were performed in wide-angle x-ray scattering (WAXS) from $15^{\circ}$ to $27^{\circ}$ with a scan speed and a step width of $4^{\circ} / \mathrm{min}$ and $0.02^{\circ}$, respectively. The crystallization temperature for the experiments in this section was changed from 25 to 18 ${ }^{\circ} \mathrm{C}$ because the x-ray diffraction intensity of the sample crystallized at $25{ }^{\circ} \mathrm{C}$ was too weak. At 15,30 and 60 min of the crystallization time, $1 \mathrm{~g}$ of the sample was carefully taken from the glass cell and gently placed in the x-ray sample holder and the polymorphic structure of the sample was characterized.

\section{Analysis of triacylglycerol composition}

The TAG composition of the original MKF and the solid fraction of MKF that crystallized at 5 min of isothermal time for the experiment both without and with the application of HIU (70\% amplitude) was analyzed using high performance liquid chromatography (HPLC) (Shimadzu LC-20AD, Shimadzu Corp, Japan) with system controller CBM-20A and diode array detector SPD-M20A. The sample was vacuum filtered to obtain the solid fraction that had crystallized during the 0 - $5 \mathrm{~min}$. This was to identify the TAG species that crystallized early in the sample without and with HIU application. Two reverse C-18 columns (Inertsil ODS-3; 4.6 x $250 \mathrm{~mm} ; 5 \mu \mathrm{m}$ particle size; by GL Sciences Inc., Japan) were used in series. Mobile phase was mixture of HPLC-grade acetone and acetonitrile in a volume-to-volume ratio of 70:30 and the flow rate was fixed at $0.72 \mathrm{~mL} / \mathrm{min}$. The column temperature was set at $30{ }^{\circ} \mathrm{C}$ with a column heater (Shimadzu 
CTO-10AS column oven). The injection volume was $20 \mu \mathrm{L}$. Identification of TAGs was conducted based on the retention time of TAG standards. All TAG contents were given in percentage area.

\section{Statistical analysis}

All experiments were performed in triplicate and the results were analyzed using ANOVA. Differences were considered statistically significantly different at $p<0.05$.

\section{Results and discussion}

\section{Crystallization kinetics}

The crystallization of the MKF samples at $25{ }^{\circ} \mathrm{C}$ without and with the application of HIU is given in Fig. 1 as a plot of changes in the normalized light intensity versus time. Although measurements were executed in triplicate, this graph represents one exemplary curve of each experiment, as there was small variation between the repetitions. At the beginning, all samples were clear liquids hence the light intensity that went through all samples was at the maximum value of 1 . Once the crystallization started, the transmitted light intensity began to drop. The HIU-treated samples with the amplitudes of 70 and $50 \%$ of the maximum value began to crystallize first with a crystallization induction time of 3 min (Table 1) where the transmitted light intensity of the two samples started to decrease very rapidly to reach the minimum value of 0 at 12 and $16 \mathrm{~min}$, respectively. At $4 \mathrm{~min}$ of the isothermal time, the HIU-treated sample with the amplitude of $30 \%$ of the maximum value was next to begin the crystallization and the minimum value of the transmitted light intensity was reached at $29 \mathrm{~min}$. The MKF without HIU application was the last sample to solidify at 6 min and the crystallization proceeded with the lowest rate to reach the plateau region of transmitted light intensity at $36 \mathrm{~min}$. Fig. 1 shows that with the application of HIU at the beginning of the isothermal time, the induction time of crystallization for the MKF fat was reduced and the crystallization reached equilibrium faster, suggesting that HIU increased the driving force for the crystallization and that HIU induced the primary nucleation in the system. The results were in line with many previous published works. For example, HIU was reported to induce the crystallization of interesterified soybean oil (Silva et al., 2017), anhydrous milk fat (Martini et al., 2008) and palm oil (Patrick et al., 2004; Chen et al., 2013; Ye and Martini, 2015) and low saturated shortening (Ye et al., 2011) with reduced induction time and increased crystallization rate. It is believed that HIU induces crystallization because cavitation bubbles generated during sonication provide a large number of heterogeneous nucleation sites with reduced activation energy barrier for nucleation, leading to a reduction of the crystallization induction time (Wohlgemuth, 2009, Chen et al., 2013). In addition, it was reported that HIU enhanced the mass transfer in the system (Luque de Castro and Priego-Capote, 2007), which could also contribute to faster crystallization. Silva et al. (2017) mentioned that greater induction in crystallization was observed when HIU is applied at the onset of crystallization. However, in this work, HIU was applied before the crystallization began and it was still effective. The same authors also reported that the effect of HIU on the crystallization induction time was dependent on the supercooling used with the HIU effect being compromised under extreme supercooling.

The time duration taken for the normalized light intensity to decrease from 0.8 to 0.2 were $12,8.2,5$ and $3.3 \mathrm{~min}$ for the samples crystallized without HIU and with HIU amplitudes of 30, 50 and $70 \%$, respectively, suggesting that the crystallization rate of MKF increased as the HIU intensity increased. The increase in the crystallization rate with increasing the HIU intensity was reported in the literature. Chen et al. (2013) reported that ultrasound greatly reduced the crystallization time to reach the equilibrium without changing the SFC of the sample. Increasing the HIU intensity leads to a heavier flow pattern in the crystallizer (Luque de Castro and Priego-Capote, 2007) and this could contribute to the increase in the crystallization rate. During sonication, the sample temperature increased to approximately 25.7, 29.2 and $32.8 \operatorname{deg} \mathrm{C}$ for the HIU amplitudes of 30, 50 and $70 \%$, respectively, before decreasing to $25 \mathrm{degC}$ within a few minutes. The fact that the sample with the HIU application crystallized with shorter induction time, hence at higher temperature, suggested that HIU raised the nucleation temperature resulting in the decrease in the supersaturation limit (Luque de Castro and Priego-Capote, 2007). HIU decreases the apparent order of primary nucleation rate and increases the rate of appearance of solid, leading to the reduced metastable zone width where a supersaturated 
solution is much more unstable under an HIU field (Luque de Castro and Priego-Capote, 2007).

\section{Crystal microstructure}

The amount of crystalline material in a fat system influences the texture and hardness of a fat crystal network (Frydenberg et al., 2013). HIU can be used to control the crystal habit and the crystal size (Ruecroft et al., 2005). The evolution of crystal morphology with time for MKF crystallized without and with HIU (30\% and $70 \%$ amplitudes) at $25 \mathrm{degC}$ are shown in Fig. 2. At 1 min of the isothermal time, the sample without HIU application was still a complete liquid whereas the HIU-treated samples with $30 \%$ and $70 \%$ amplitudes had already started to solidify with small crystals $(5.6+-1.18$ and $6.3+-0.84 \mu \mathrm{m}$, respectively) scattering against the dark liquid background. At $10 \mathrm{~min}$, the MKF from the experiment without the HIU treatment showed a few crystals $(19.6 \pm 1.92 \mu \mathrm{m})$ and the crystals of the HIU-treated samples were larger $(20.9 \pm 2.37$ and $23.4 \pm$ $3.72 \mu \mathrm{m}$ for HIU amplitudes $30 \%$ and $70 \%$, respectively) with an increase in the number of crystal compared to $1 \mathrm{~min}$. At 30 and $60 \mathrm{~min}$, the crystals of the samples from all treatments were spherulites and the crystal number and the crystal size had increased with time. The MKF crystallized without the application of HIU had the largest crystal size $(97.9 \pm 6.47$ and $114.3 \pm 4.08 \mu \mathrm{m}$ for 30 and $60 \mathrm{~min}$, respectively) but with the lowest number of crystals, suggesting that crystal growth process was dominating. In contrast, MKF crystalized with the application of HIU with $70 \%$ amplitude exhibited the smallest crystal size $(33.5 \pm 2.18$ and $43.8 \pm 1.83 \mu \mathrm{m}$ for 30 and $60 \mathrm{~min}$, respectively) but the highest number of crystals, indicating that crystal nucleation process was dominating. The decrease in the crystal size could be related to the shear forces associated with ultrasound that act to slow growth processes (Nalajala and Moholkar, 2011). This was similar to the effect of HIU on the microstructure of anhydrous milk fat reported by Frydenberg et al. (2013) and Martini et al. (2008). In addition, higher viscosities were recorded when samples crystalized after HIU application (Martini et al., 2008), which could delay the crystal growth process, leading to small crystal size. Luque de Castro and Priego-Capote (2007) reported a decrease in crystal size and an increase in crystal number, with a clear involvement of an abrasion effect, when the power of the applied HIU increased. It was possible that the formation and collapse of cavitation provided the increasing possibility of nucleation for the samples. An increase in the number of smaller crystals typically results in increased fat crystal network strength (Tran and Rousseau, 2016). Changes observed in crystal morphology due to sonication can be attributed to the formation of different molecular compounds or to the presence of different polymorphic forms, hence, the TAG composition and the polymorphic form of MKF that crystallized without and with the application of HIU were investigated in the following sections.

\section{Melting characteristic}

The evolution of the melting characteristic with time of MKF crystallized at $25{ }^{\circ} \mathrm{C}$ without and with HIU application is given in Fig. 3. For the crystallization without HIU, the sample did not exhibit any peak at $\mathrm{t}$ $=5 \mathrm{~min}$ (Fig. 3a). At 15-30 min, the sample started to melt at $27.6-27.7{ }^{\circ} \mathrm{C}$ and showed a relatively broad melting peak at $28-29{ }^{\circ} \mathrm{C}$ (Table 2). At 45 and $60 \mathrm{~min}$, the sample began to melt at higher temperature ( 31 $\operatorname{deg} \mathrm{C}$ ) and the melting peak became much broader, the location of which moved to a significantly higher peak temperature of $35 \operatorname{deg} \mathrm{C}(p<0.05)$ with a decrease in the melting enthalpy $(\Delta \mathrm{H})(p<0.05)$. This suggests that there was a phase transition of MKF from a less stable form to a more stable one after $30 \mathrm{~min}$ of crystallization. With HIU ( $70 \%$ amplitude), MKF had already started to crystallize at 5 min with one melting peak at $28{ }^{\circ} \mathrm{C}$ (Fig. $3 \mathrm{~b}$ and Table 2), indicating that, at the early stages, MKF in the experiments without and with HIU solidified into the same polymorphic structure $(p>0.05)$. At $15 \mathrm{~min}$, the melting

peak location moved to $33 \operatorname{deg} \mathrm{C}$ with a decrease in $\Delta \mathrm{H}$, indicating the polymorphic transformation of MKF at this crystallization time and suggesting that the phase transition of MKF that crystallized with the application of HIU occurred sooner than MKF that crystallized without HIU. At 45 and 60 min, the melting peak moved to higher temperature $\left(35^{\circ} \mathrm{C}\right)$ with an increase in $\Delta \mathrm{H}$ from that of $15 \mathrm{~min}$.

\section{Polymorphic structure}

The polymorphic form of MKF crystallized at $18{ }^{\circ} \mathrm{C}$ without and with the HIU application is shown in Fig. 4. Without the application of HIU, MKF crystallized into $\beta^{\prime}$ structure at 15 and 30 min of crystallization 
with a diffraction peak in wide-angle scattering at $4.14 \AA$. At $60 \mathrm{~min}$, the sample showed the coexistence of $\beta^{\prime}$ and $\beta$ (4.6 $\AA$ ) polymorphs, indicating that the $\beta^{\prime}-\mathrm{b}$ transition was ongoing between 30 and 60 min of crystallization time. With the application of HIU (70\% amplitude), the sample solidified into $\beta$ ' polymorph at $15 \mathrm{~min}$ and at $30 \mathrm{~min}$ it was already in the mixture of $\beta^{\prime}$ and $\beta$ polymorphs. At $60 \mathrm{~min}, \beta$ form was the dominant polymorph. It can be seen from the results that the $\beta^{\prime}$-b transformation started to occur sooner in thesample that crystallized with HIU. HIU was found to accelerate $\beta$ '-b transition in CB (Higaki et al., 2001), promote the formation of $\beta^{\prime}$ crystal polymorph in anhydrous milk fat (Frydenberg et al., 2013) and promote $\beta$ crystal formation for tripalmitin and trilaurin (Ueno et al., 2003). Acceleration of crystallization is of great significance to the food industry as this could shorten the processing time and hence reduce processing costs. (Frydenberg et al., 2013). These results correlate well with the results obtained by DSC.

\section{Triacylglycerol composition}

The TAG compositions of the original MKF and the solid fraction of MKF that crystallized at 5 min of isothermal time for the experiment both without and with the application of HIU (70\% amplitude) are given in Table 1. The main TAG species in MKF were SOS (45.5\%), SOO (27.3\%) and POS (12\%). Similar results were observed by Sneha and Jeyarani (2018) and Jin et al. (2016). In the solid fractions crystallized without and with HIU, the contents of triunsaturated, diunsaturated and monounsaturtaed TAGs (i.e., OOO, POO, POP, SOO, POS and OOAr) decreased whereas the contents of trisaturated TAGs (i.e., SSP and SSS) and the high-melting monounsaturated TAGs (i.e., the symmetric SUS TAGs like SOS and SOAr) increased $(p<0.05)$. The contents of both SSP and SSS in the solid fraction crystallized with HIU were higher than those in the solid fraction crystallized without HIU $(p<0.05)$, suggesting that HIU increased the crystallization of high-melting TAGs at the early stages of crystallization (Kadamne et al., 2017). Frydenberg et al. (2013) suggested that HIU could affect the crystallization of specific TAGs. These high-melting TAGs had a tendency to crystallize into $\beta$ structure leading to the acceleration of $\beta$ '-b in the sample.

There is most likely more than one mechanism to explain the effect of HIU on crystallization. This includes the increase in the melting point in the vicinity of the collapsing cavity due to the local pressure changes, leading to an increase in the degree of super cooling. The cavitation bubbles and violent collapse can form active sites for secondary nucleation. In addition, the shear forces and the turbulence generated by sonication can influence the crystallization kinetics (Chandrapala and Leong, 2015). The faster polymorphic transition could be due to the shear forces generated during HIU application. Shear could influence the structure of the nanoplatelets formed upon nucleation which then act as templates for higher, more-organized polymorphs (Maleky et al., 2011). This work has demonstrated that HIU can affect the crystallization of MKF and the effect was dependent on the amplitude of the HIU applied. The crystallization induction time reduced, the crystal size decreased and the crystal number increased with the HIU application. In addition, the polymorphic transition of the fat was accelerated by HIU. This suggests that HIU can be used to temper MKF when it is being used as a confectionery fat in food products such as chocolate.

\section{Conclusion}

This research demonstrated that HIU had an effect on the crystallization of MKF. With HIU, the crystallization induction time was reduced; the crystal size became smaller with an increase in the crystal number. The effect was stronger when HIU with higher amplitude was applied. More importantly, HIU accelerated $\beta^{\prime}$-b transition of MKF. Therefore, HIU has a potential as an alternative processing method for tempering the chocolate and confectionery products that contain MKF or other fats rich in monounsaturated TAGs such as CB.

\section{References}

Chandrapala, J., \& Leong, T. (2015) Ultrasonic Processing for Dairy Applications: Recent Advances. Food Engineering Reviews , 7 :143-158.

Chen, F., Zhang, H., Sun, X., Wang, X., \& Xu, X. (2013) Effects of ultrasonic parameters on the crystallization behavior of palm oil.Journal of the American Oil Chemists' Society, 90 :941-949. 
Fritsch, J., Stille, W., \& Strobl, G. (2006) Investigation of polymer crystallization kinetics with time dependent light attenuation measurements. Colloid and Polymer Science, 284 :620-626.

Frydenberg, R. P., Hammershøj, M., Andersen, U., \& Wiking, L. (2013) Ultrasonication affects crystallization mechanisms and kinetics of anhydrous milk fat. Crystal Growth $\mathscr{E}$ Design ,13 :5375-5382.

Higaki, K., Ueno, S., Koyano, T., \& Sato, K. (2001) Effects of ultrasonic irradiation on crystallization behavior of tripalmitoylglycerol and cocoa butter. Journal of the American Oil Chemists' Society , 78 :513-518.

Jin, J., Warda, P., Mu, H. Y., Zhang, Y. F., Jie, L., Mao, J. H., Xie, D., Huang, J. H., Jin, Q. Z., \& Wang, X. G. (2016) Characteristics of mango kernel fats extracted from 11 china-specific varieties and their typically fractionated fractions. Journal of the American Oil Chemists' Society, 93 :1115-1125.

Kadamne, J.V., Ifeduba, E.A., Akoh, C.C., Martini, S. (2017) Sonocrystallization of Interesterified Fats with 20 and $30 \%$ of Stearic Acid at the sn -2 Position and Their Physical Blends. Journal of the American Oil Chemists' Society, 94 :1045-1062.

Li, H., Li, H., Guo, Z., \& Liu, Y. (2006) The application of power ultrasound to reaction crystallization. Ultrasonics Sonochemistry, $13: 359-363$.

Luque de Castro, M. D., \& Priego-Capote, F. (2007) Ultrasound-assisted crystallization (sonocrystallization). Ultrasonics Sonochemistry, $14: 717-724$.

Maleky, F., Smith, A. K., \& Marangoni, A. (2011) Laminar shear effects on the crystalline alignments and nanostructure of a triacylglycerol crystal network. Crystal Growth $\&$ Design ,11:2335-2345.

Martini, S., Suzuki, A. H., \& Hartel, R. W. (2008) Effect of high intensity ultrasound on crystallization behavior of anhydrous milk fat.Journal of the American Oil Chemists' Society,85:621-628.

Mason, T. J., Paniwnyk, L., \& Lorimer, J. P. (1996) The uses of ultrasound in food technology, Ultrasonics Sonochemistry, 3 :S253-S260.

Mulin, J. W. (2001) Crystallization, $4^{\text {th }}$ ed., Butterworth-Heinemann, Woburn, MA.

Nalajala, V. S., \& Moholkar V. S. (2011) Investigations in the physical mechanism of sonocrystallization. Ultrasonics Sonochemistry, $18: 345-355$.

Patist, A., \& Bates, D. (2008) Ultrasonic innovations in the food industry: From the laboratory to commercial production. Innovative Food Science and Emerging Technology, 9 :147-154.

Patrick, M., Blindt, R., \& Janssen, J. (2004) The effect of ultrasonic intensity on the crystal structure of palm oil. Ultrasonics Sonochemistry, $11: 251-255$.

Ruecroft, G., Hipkiss, D., Ly, T., Maxted, N., \& Cains, P.W. (2005) Sonocrystallization: The use of ultrasound for improved industrial crystallization. Organic Process Research and Development, ,9 :923-932.

Silva, R. C., Lee, J., Gibon, V., \& Martini, S. (2017) Effects of high Intensity ultrasound frequency and high-speed agitation on fat crystallization. Journal of the American Oil Chemists' Society, 94:1063-1076.

Sneha, R., \& Jeyarani, T. (2018) Lipase-catalysed acidolysis of mango kernel fat with capric acid to obtain medium- and long-chain triacylglycerols. International Journal of Food Science and Technology, 53 :15271534 .

Sonwai, S., Kaphueakngam, P., \& Flood, A. (2014) Blending of mango kernel fat and palm oil mid-fraction to obtain cocoa butter equivalent. Journal of Food Science and Technology , 51 :2357-2369.

Soria, A. C., \& Villamiel, M. (2010) Effect of ultrasound on the technological properties and bioactivity of food: A review. Trends in Food Science and Technology, 21 :323-331. 
Suzuki, A. H., Lee, J., Padilla, S. G., \& Martini, S. (2010) Altering functional properties of fats using power ultrasound. Journal of Food Science, 75 :E208-E214.

Tiang, J. S., \& Dealy, J. M. (2012) Shear-induced crystallization of isotactic polypropylene studied by simultaneous light intensity and rheological measurements. Polymer Engineering and Science, 52 :835-848.

Tran, T., \& Rousseau, D. (2016) Influence of shear on fat crystallization. Food Research International ,81 $: 157-162$.

Ueno, S., Ristic, R. I., Higaki, K., \& Sato, K. (2003) In situ studies of ultrasound-stimulated fat crystallization using synchrotron radiation. Journal of Physical Chemistry , 107 :4927-4935.

Wilson, E. (1999) Chocolate: the $5 \%$ option... What if?.Manufacturing Confectioner , 11 :47-51.

Wohlgemuth, K., Kordylla, A., Ruether, F., \& Schembecker, G. (2009) Experimental study of the effect of bubbles on nucleation during batch cooling crystallization. Chemical Engineering Science, 64 :4155-4163.

Wright, A. J., Narine, S. S., \& Marangoni, A.G. (2000) Comparison of experimental techniques used in lipid crystallization studies. Journal of the American Oil Chemists' Society ,77 :1239-1242.

Ye, Y., \& Martini, S. (2015) Application of high-intensity ultrasound to palm oil in a continuous system. Journal of Agricultural and Food Chemistry, 63 :319-327.

Ye, Y., Wagh, A., Martini, S. (2011) Using high intensity ultrasound as a tool to change the functional properties of interesterified soybean oil. Journal of Agricultural and Food Chemistry, 59:10712-10722.

\section{Figure Legends}

Figure 1 Changes in normalized light intensity as a function of time during crystallization of MKF with and without the application of HIU with different amplitudes for $5 \mathrm{~s}$ at $25 \mathrm{degC}$.

Figure 2 Changes in crystal microstructure of MKF as a function of time during crystallization with and without the application of HIU with different amplitudes for $5 \mathrm{~s}$ at $25 \operatorname{degC}$.

Figure 3 DSC melting thermogram of MKF obtained after crystallization at 25 degC for different duration (a) without HIU and (b) with HIU $70 \%$ for 5 s.

Figure 4 XRD diffraction patterns of MKF obtained after crystallization at 18 degC for different duration (a) without HIU and (b) with HIU $70 \%$ for 5 s.

\section{Hosted file}

image1. emf available at https://authorea.com/users/307817/articles/438770-high-intensity-ultrasoundinduced-crystallization-of-mango-kernel-fat

Fig. 1

Fig. 2

\section{Hosted file}

image14.emf available at https://authorea.com/users/307817/articles/438770-high-intensity-ultrasoundinduced-crystallization-of-mango-kernel-fat

\section{Hosted file}


image15.emf available at https://authorea.com/users/307817/articles/438770-high-intensity-ultrasoundinduced-crystallization-of-mango-kernel-fat

Fig. 3

\section{Hosted file}

image16.emf available at https://authorea.com/users/307817/articles/438770-high-intensity-ultrasoundinduced-crystallization-of-mango-kernel-fat

Fig. 4

Table 1 Crystallization induction time during static crystallization at $25{ }^{\circ} \mathrm{C}$ of mango kernel fat without and with the application of high intensity ultrasound (HIU) with different amplitudes (30\%, 50\% and 70\% of the maximum value) obtained via the light intensity measurement.

\begin{tabular}{ll}
\hline Experiment & Induction time $(\min )$ \\
\hline No HIU With HIU-30\% With HIU-50\% With HIU-70\% & $5.40 \pm 0.76^{\mathrm{c}} 4.06 \pm 0.49^{\mathrm{b}} 2.69 \pm 0.81^{\mathrm{a}} 2.56 \pm 1.02^{\mathrm{a}}$ \\
\hline
\end{tabular}

Table 2 DSC onset $\left(\mathrm{T}_{\mathrm{ON}}\right)$, peak $\left(\mathrm{T}_{\mathrm{P}}\right)$ and end $\left(\mathrm{T}_{\mathrm{END}}\right)$ temperatures and enthalpy $(\Delta \mathrm{H})$ obtained during melting of mango kernel fat that crystallized for different durations without and with the application of high intensity ultrasound (HIU) (70\% amplitude).

Experiment

TON

No HIU 5 min $15 \min 30 \min 45 \min 60 \min$ With HIU $5 \min 15 \min 30 \min 45 \min 60 \min -27.6 \pm 0.41^{\mathrm{b}} 27.7 \pm 0.27^{\mathrm{b}}$

Table 3 Triacylglycerol (TAG) composition of the original mango kernel fat (MKF) and the solid fractions of MKF that crystallized for 5 min of isothermal time for the experiment both without and with the application of high intensity ultrasound (HIU) (70\% amplitude). ( $\mathrm{O}=$ oleic acid, $\mathrm{P}=$ palmitic acid, $\mathrm{S}=$ stearic acid, Ar $=$ arachidic acid).

\begin{tabular}{llll}
\hline TAG & MKF & Solid fraction & Solid fraction \\
\hline & & No HIU & With HIU \\
OOO & $3.34 \pm 0.23^{\mathrm{a}}$ & $2.54 \pm 0.17^{\mathrm{b}}$ & $2.47 \pm 0.12^{\mathrm{b}}$ \\
POO & $2.63 \pm 0.19^{\mathrm{a}}$ & $2.34 \pm 0.09^{\mathrm{b}}$ & $1.67 \pm 0.20^{\mathrm{c}}$ \\
POP & $1.59 \pm 0.28^{\mathrm{a}}$ & $1.27 \pm 0.13^{\mathrm{a}}$ & $1.26 \pm 0.17^{\mathrm{a}}$ \\
SOO & $27.28 \pm 1.14^{\mathrm{a}}$ & $20.70 \pm 0.92^{\mathrm{b}}$ & $20.10 \pm 0.86^{\mathrm{b}}$ \\
POS & $12.00 \pm 0.87^{\mathrm{a}}$ & $10.79 \pm 0.64^{\mathrm{a}}$ & $10.90 \pm 0.39^{\mathrm{a}}$ \\
OOAr & $2.27 \pm 0.16^{\mathrm{a}}$ & $1.96 \pm 0.08^{\mathrm{b}}$ & $1.94 \pm 0.11^{\mathrm{b}}$ \\
SOS & $45.47 \pm 1.35^{\mathrm{b}}$ & $48.07 \pm 0.97^{\mathrm{a}}$ & $47.95 \pm 1.02^{\mathrm{a}}$ \\
SSP & - & $1.19 \pm 0.17^{\mathrm{b}}$ & $1.71 \pm 0.26^{\mathrm{a}}$ \\
SOAr & $5.38 \pm 0.69^{\mathrm{b}}$ & $6.92 \pm 0.56^{\mathrm{a}}$ & $6.78 \pm 0.33^{\mathrm{a}}$ \\
SSS & - & $4.18 \pm 0.37^{\mathrm{b}}$ & $5.20 \pm 0.24^{\mathrm{a}}$ \\
\hline
\end{tabular}

